\title{
Commentary: Cerebellar Ataxia, Neuropathy, Vestibular Areflexia Syndrome (CANVAS) with Chronic Cough and Preserved Muscle Stretch Reflexes: Evidence for Selective Sparing of Afferent la Fibres
} José Berciano'*, Antonio García², Jon Infante'

'Service of Neurology, University Hospital "Marqués de Valdecilla (IDIVAL)", University of Cantabria, and "Centro de Investigación Biomédica en Red de Enfermedades Neurodegenerativas (CIBERNED)", Santander, Spain

${ }^{2}$ Service of Clinical Neurophysiology, University Hospital "Marqués de Valdecilla (IDIVAL)", and "Centro de Investigación Biomédica en Red de Enfermedades Neurodegenerativas (CIBERNED)", Santander, Spain

\section{Article Info}

\section{Article Notes}

Received: October 3, 2019

Accepted: November 6, 2019

\section{${ }^{*}$ Correspondence:}

Dr. José Berciano, Professor Emeritus, Department of Medicine and Psychiatry, University of Cantabria, EUE Building 4th

Floor, Avda. Valdecilla s/n, 39008 Santander, Spain; E-mail: josebercian051@hotmail.com.

(c) 2019 Berciano J. This article is distributed under the terms of the Creative Commons Attribution 4.0 International License

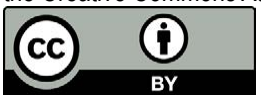

\section{Keywords:}

Cerebellar Ataxia with Neuropathy and Vestibular Areflexia Syndrome (CANVAS)

Spasmodic Cough

Tendon Jer

T-Reflex

\section{Abstract}

Cerebellar ataxia with neuropathy and vestibular areflexia syndrome (CANVAS) is a form of ataxia characterized by the combination of bilateral vestibular, cerebellar and somatosensory impairment. In this commentary we summarized our report of five CANVAS cases presenting with spasmodic cough, which antedated the appearance of imbalance in several decades. Furthermore, in the hallmark of a severe sensory ataxia, tendon jerks and T-reflex recordings were almost completely preserved; sparing of muscle spindle afferents (fibres la) is probably the pathophysiological basis of normoreflexia.

\section{Introduction}

Cerebellar ataxia with neuropathy and vestibular areflexia syndrome (CANVAS) is an uncommon, late-onset form of ataxia characterized by the combination of bilateral vestibular, cerebellar and somatosensory impairment ${ }^{1,2}$.

The somatic sensory deficit contributes to a significant level of disability in CANVAS $^{3,4}$. Neurophysiological studies have revealed an almost constant absence of sensory nerve action potentials (SNAP) in upper- and-lower limb nerves, and somatosensory evoked potentials (SEP) ${ }^{4-6}$. The pathological background is a severe dorsal root ganglionopathy with secondary degeneration of central and peripheral sensory axons ${ }^{7}$. Despite these electrophysiological and pathological features should be closely associated with generalized areflexia, intact muscle stretch reflexes have been reported in a significant proportion of CANVAS patients ${ }^{2,3}$. The pathophysiology of such clinicalelectrophysiological discordance remains unexplained.

Chronic cough has been described in association with several genetic disorders involving the autonomic nervous system, such as HolmesAdie syndrome, Charcot-Marie-Tooth disease type 2J, dominant ataxia, and hereditary sensory and autonomic neuropathy (HSAN) ${ }^{8-11}$. Chronic cough and autonomic dysfunction may be an integral part of the clinical picture in CANVAS ${ }^{2,12}$.

Herewith, we have summarized our description of five CANVAS patients presenting with chronic, idiopathic cough; all of them showed severe somatosensory deficit with preserved tendon reflexes and T-reflex recordings ${ }^{13}$. 


\section{Patients and Methods}

The study is based upon five CANVAS patients, four of them belonging to two non-consanguineous families (for pedigrees, see figure 1 in reference 1), attended by us between 2006 and 2017. The severity of ataxia was graded according to IAPS ${ }^{14}$ (Table 1 ).

All five patients were thoroughly investigated with screens for acquired causes of spinocerebellar degeneration including toxic, metabolic and systemic disorders (thyroid hormone levels, vitamin B12 deficiency, serology for celiac disease and Sjögren' syndrome, and tumour markers). Molecular screening for Friedreich's ataxia (FA) and spinocerebellar ataxia (SCA) (SCA1, SCA2, SCA3, SCA6, SCA7, SCA8, SCA12, SCA17 and DRPLA) was performed.

Non-contrasted magnetic resonance imaging (MRI) study of the brain was performed in all five patients.

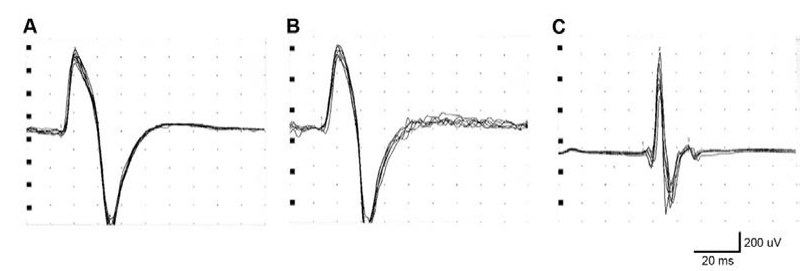

Figure 1. Normal recordings of biceps brachii T-reflex (A, case 3; $\mathrm{B}$, case 5 ) and Achilles T-reflex (C, case 3 ) (for patient numbering, see Table 1)
Electrophysiology in four cases comprised nerve conduction studies (median, ulnar, peroneal, tibial and sural nerves), T-reflex recordings [biceps brachii T-reflex, patellar T-reflex, soleus T-reflex (Achilles T-reflex) and masseter reflex], needle electromyography, SEP, and sympathetic skin response (SSR). The diagnosis of bilateral vestibulopathy was based on diagnostic criteria of the Classification Committee of the Bárány Society ${ }^{15}$.

\section{Results}

Clinical features of all five patients appear summarized in Table 1. Cases 1 and 2 were first cousins, and cases 3 and 4 were sisters; case 5 was sporadic. There were 4 females and 1 male. Ages of patients ranged from 60 and 68 years (median 66) with gait instability initiated between 41 and 49 years (median 46 ).

All five patients fulfilled the diagnosis of bilateral vestibulopathy ${ }^{15}$, namely: i/ the patient history of unsteadiness when walking or standing, which worsen in darkness, uneven ground or during head motion; ii/ no symptoms while sitting or lying down; iii/ bilaterally pathological horizontal angular vestibulo-ocular reflex (VOR) gain < 0.6 (at video head impulse test [vHIT]) and/ or reduced caloric response (sum of bithermal maximal peak slow phase velocity on each side $<6 \% / \mathrm{sec}$ ), and/ or reduced VOR gain 0.1 upon sinusoidal stimulation on a rotatory chair $(0.1 \mathrm{~Hz}, \operatorname{Vmax}=50 \mathrm{o} / \mathrm{sec})$ and phase lead $>68$ degrees (time constant $<5 \mathrm{sec}$ ); and iv/ not better accounted for by another disease. We will herewith focus

Table 1. Summary of clinical data at last examination.

\begin{tabular}{|c|c|c|c|c|c|}
\hline & Case No. & & & & \\
\hline Parameter & 1 & 2 & 3 & 4 & 5 \\
\hline Sex & $\mathrm{M}$ & $\mathrm{F}$ & $\mathrm{F}$ & $\mathrm{F}$ & $\mathrm{F}$ \\
\hline Age & 68 & 68 (at death) & 60 & 61 & 66 \\
\hline Age of onset & 33 & 30 & $\sim 20$ & 46 & $\sim 20$ \\
\hline Initial symptoms & $\begin{array}{l}\text { Chronic cough. } \\
\text { As of age } 48, \\
\text { gait instability }\end{array}$ & $\begin{array}{l}\text { Chronic cough. } \\
\text { As of age } 45, \\
\text { gait instability }\end{array}$ & $\begin{array}{l}\text { Chronic cough. } \\
\text { As of age } 49, \\
\text { gait instability }\end{array}$ & $\begin{array}{l}\text { Chronic cough. } \\
\text { and gait } \\
\text { instability }\end{array}$ & $\begin{array}{l}\text { Chronic cough. } \\
\text { As of age } 41, \\
\text { gait instability }\end{array}$ \\
\hline Lower-limb hypopallesthesia & $3+$ & $3+$ & $3+$ & $3+$ & $3+$ \\
\hline Postural rombergism & $2+$ & $\mathrm{NE}$ & $3+$ & $3+$ & $3+$ \\
\hline Gait instability & $3+$ & $\mathrm{NE}$ & $3+$ & $3+$ & $1+$ \\
\hline Finger-to-nose ataxia & $1+$ & $2+$ & - & $1+$ & - \\
\hline Heel-knee ataxia & $2+$ & $2+$ & $1+$ & $1+$ & $1+$ \\
\hline Dysarthria & $2+$ & $3+$ & - & - & - \\
\hline Gaze-evoked nystagmus & Present & Present & Present & Present & - \\
\hline Upper-limb tendon jerks & Brisk & Present & Present & Present & Present \\
\hline Knee jerks & Brisk & Present & Brisk & Present & Present \\
\hline Ankle jerks & - & Hypoactive & - & Hypoactive & - \\
\hline Bilateral vestibulopathy & Present & Present & Present & Present & Present \\
\hline IAPS stage & 3 & 4 & 2 & 2 & 2 \\
\hline
\end{tabular}

$(-)=$ absent; $(+)=$ mild; $(2+)=$ moderate; $(3+)=$ severe

IAPS = Inherited Ataxia Progression Scale; stage 1, asymptomatic; stage 2, symptoms present but mild; stage 3, fully developed symptoms, patient needs constant care; and stage 4, wheelchair bound

$\mathrm{NE}=$ no evaluable (patient wheelchair bound) 
on two particular semeiological aspects: spasmodic cough and tendon reflexes.

Non-specific, diurnal, chronic and dry cough was the initial manifestation antedating gait instability from 15 to 29 years, excepting in case 4 who noticed the simultaneous occurrence of cough and gait disturbances (Table 1). Coughing usually came in bursts sometimes triggered by various factors: cold air, bending down or rising after sleep, eating bananas, dry foods or spicy foods, inhalation of strong odours or dusts, strong speaking aloud, long telephonic conversations, and shouting. Neither stimulation the external auditory meatus with a cotton nor otoscopic procedures triggered cough reflex (Arnold's ear-cough reflex) in any of the patients. The frequency of the cough bursts was variable over time, ranging from occasional throughout the year to almost daily presentation, duration varying between few seconds and several hours. None of the patients received cough-induced drugs (eg, enalapril). Associated symptoms included scratchy and dry throat and voice changes, but none of the patients had dysphagia or syncope. Only patient 5 referred to symptoms of gastrooesophageal reflux disease, which responded to lifestyle modification and anti-acid drugs with no changes to the frequency of cough bursts. Patients were evaluated by their general physicians and lung specialists without observing respiratory diseases or allergies; none of them did smoke. Several antitussives medications were administered in patient 1, just codeine phosphate being partially efficacious. Only in this patient, the coughing episodes tended to attenuate after the onset of ataxia. There were no other possible manifestations of dysautonomia, including persistent diarrhoea or constipation, sphincter disturbances, erectile dysfunction, dry eyes/mouth, sweating changes, or orthostatic intolerance.

All five patients showed postural imbalance and unsteadiness of gait, both of which worsened in darkness and on uneven ground, occasionally being accompanied by oscillopsia (Table 1). None of them noticed hearing loss. All five patients showed marked vibratory hypopallesthesia up to iliac crests, and to a lesser degree in hands and forearms. There was positive Romberg sign and gait imbalance (see Supplementary material, video-recordings in reference 13) and stocking and glove tactile and pain hypoesthesia. Upper-limb and knee jerks were either preserved or brisk, whereas ankle jerks were hypoactive or absent (Table 1); jaw jerk was systematically absent; and plantar responses, where obtainable, were flexor.

Serial evaluation of patient 3 was done over 6 years (see reference 13 for further details). At initial examination she showed pure postural rombergism, a working diagnosis of AR-HSAN being given, which was replaced by spinocerebellar syndrome with the appearance of appendicular ataxia and nystagmus, and subsequent evaluation of her affected sister.
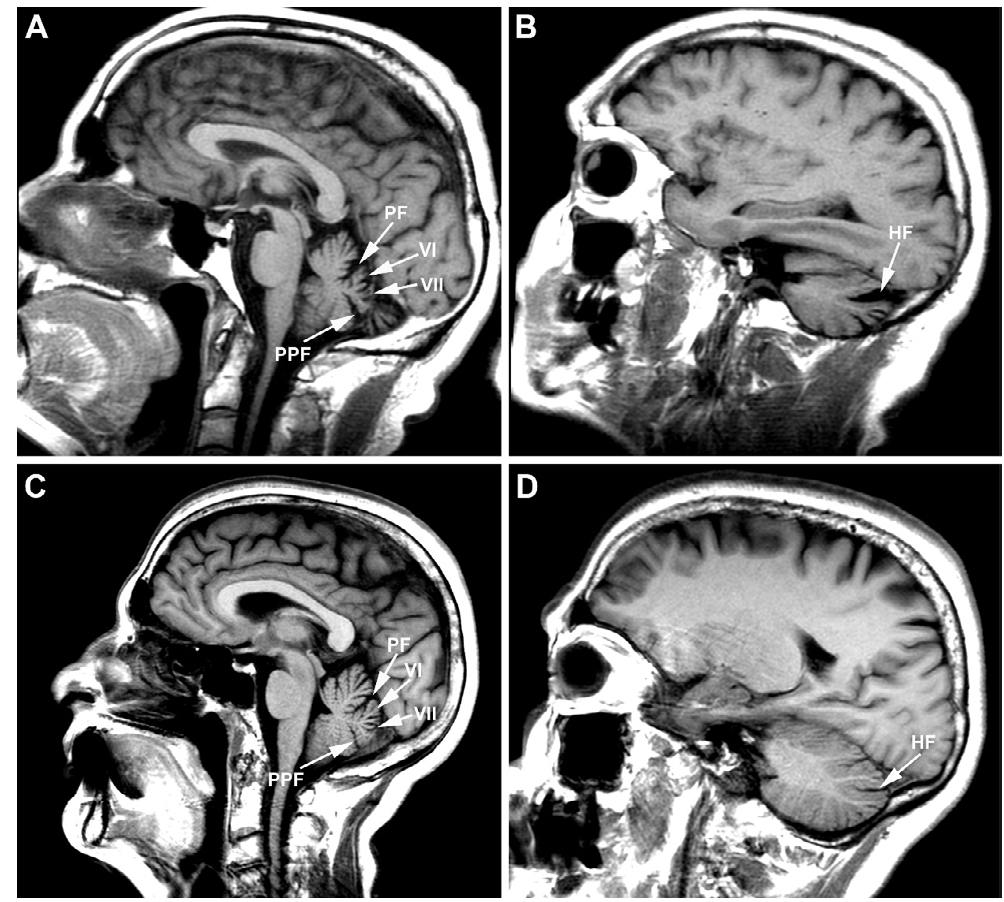

Figure 2. Cranial sagittal T1 weighted MRI images of case 1 (A, B) and case $3(C, D)$. (A) Midsagittal view showing marked vermian atrophy mainly involving declive (VI), and folium vermis and tuber vermis (VII); note enlargement of the primary fissure (PF) and prepyramidal fissure (PPF). (B) Parasagittal view illustrating enlargement of the horizontal fissure (HF). (C, D) Similar but milder findings in case 3 exhibiting minimal cerebellar signs (table 1). 
Routine laboratory data, including those to exclude toxic, metabolic and systemic disorders, were normal or negative. No dynamic mutations associated with FA or SCA were found (see above for the list of SCA tests performed).

Motor nerve conduction parameters, including $\mathrm{F}$ wave latencies, of median, ulnar, peroneal and tibial nerves were normal in every case. SNAP of median and ulnar nerves were absent. SEPs from tibial nerve were absent in all 4 examined cases, and absent or severely attenuated from median nerve. The biceps and patellar T-reflex was systematically normal, whereas Achilles T-reflex was preserved two cases (figure 1). SSR, done in four cases, was normal.

Brain MRI findings are illustrated in figure 2 (see also table 1).

\section{Conclusions}

We conclude that spasmodic cough may be an integral part of the clinical picture in CANVAS, antedating the appearance of imbalance in several decades. CANVAS is a unique normoreflexic neurodegenerative disorder associated with selective sparing of Ia fibres that subserve muscle spindle afferents, in a setting of severe somatic sensory neuronopathy with widespread central-peripheral axonopathy. The presumptive horizontal transmission in 4 of our 5 patients suggesting that CANVAS might be an autosomal recessive entity has been reinforced with recent genetic discoveries, showing biallelic intronic AAGGG repeat expansion in $R F C 1$ gene ${ }^{16,17}$. RFC1 encodes the large subunit of replication factor $\mathrm{C}$, a 5-subunit DNA accessory protein required for the coordinated synthesis of both DNA strands during replication or after DNA damage (cf. OMIM 102579). So far, approximately 40 neurological genetic disorders have been associated with nucleotide expansions. Two of them are known to be inherited in a recessive mode, namely Friedreich ataxia and myoclonic epilepsy type 1; both are associated with loss of function of the repeat hosting gene. A remarkable aspect of CANVAS is that its homozygous dynamic mutation does not seem to imply loss of function for $R F C 1^{16}$

\section{References}

1. Szmulewicz DJ, Waterston JA, Halmagyi GM, et al. Sensory neuropathy as part of the cerebellar ataxia neuropathy vestibular areflexia syndrome. Neurology. 2011; 76: 1903-10.

2. Szmulewicz DJ, McLean CA, MacDougall HG, et al. CANVAS an update: clinical presentation, investigation and management. J Vestib Res. 2014; 24: 465-74.

3. Szmulewicz DJ, Waterston JA, MacDougall HG, et al. Cerebellar ataxia, neuropathy, vestibular areflexia syndrome (CANVAS): a review of the clinical features and video-oculographic diagnosis. Ann N Y Acad Sci. 2011; 1233: 139-47.

4. Szmulewicz DJ, Seiderer L, Halmagyi GM, et al. Neurophysiological evidence for generalized sensory neuronopathy in cerebellar ataxia with neuropathy and bilateral vestibular areflexia syndrome. Muscle Nerve. 2015; 51: 600-3.

5. Migliaccio AA, Halmagyi GM, McGarvie LA, et al. Cerebellar ataxia with bilateral vestibulopathy: description of a syndrome and its characteristic clinical sign. Brain. 2004; 127: 280-93.

6. Gazulla J, Pablo-Zaro MJ, Fraile-Rodrigo J, et al. Sensory Neuronopathy in CANVAS: cerebellar ataxia, neuropathy, and vestibular areflexia. Can J Neurol Sci. 2016; 43: 604-5.

7. Szmulewicz DJ, McLean CA, Rodriguez ML, et al. Dorsal root ganglionopathy is responsible for the sensory impairment in CANVAS. Neurology. 2014; 82: 1410-5.

8. Kimber J, Mitchell D, Mathias CJ. Chronic cough in the Holmes-Adie syndrome: association in five cases with autonomic dysfunction. J Neurol Neurosurg Psychiatry. 1998; 65: 583-6.

9. Baloh RH, Jen JC, Kim G, et al. Chronic cough due to Thr124Met mutation in the peripheral myelin protein zero (MPZ gene). Neurology. 2004; 62: 1905-6.

10. Spring PJ, Kok C, Nicholson GA, et al. Autosomal dominant hereditary sensory neuropathy with chronic cough and gastro-oesophageal reflux: clinical features in two families linked to chromosome 3p22-p24. Brain. 2005; 128: 2797-810.

11. Coutinho P, Cruz VT, Tuna A, et al. Cerebellar ataxia with spasmodic cough: a new form of dominant ataxia. Arch Neurol. 2006; 63: 553-5.

12. Wu TY, Taylor JM, Kilfoyle DH, et al. Autonomic dysfunction is a major feature of cerebellar ataxia, neuropathy, vestibular areflexia 'CANVAS' syndrome. Brain. 2014; 137: 2649-56.

13. Infante J, García A, Serrano-Cárdenas KM, et al. Cerebellar ataxia, neuropathy, vestibular areflexia syndrome (CANVAS) with chronic cough and preserved muscle stretch reflexes: evidence for selective sparing of afferent Ia fibres. J Neurol. 2018; 265: 1454-1462.

14. Campanella G, Filla A, De Falco MA, et al. Friedreich's ataxia in the south of Italy; a clinical and biochemical study survey of 23 patients. Can J Neurol Sci. 1980; 7: 351-8.

15. Strupp M, Kim JS, Murofushi T, et al. Bilateral vestibulopathy: Diagnostic criteria Consensus document of the Classification Committee of the Bárány Society. J Vestib Res. 2017; 27: 177-189.

16. Cortese A, Simone R, Sullivan R, et al. Biallelic expansion of an intronic repeat in RFC1 is a common cause of late-onset ataxia. Nat Genet. 2019; 51: 649-658.

17. Rafehi H, Szmulewicz DJ, Bennett MF, et al. Bioinformatics-based identification of expanded repeats: A non-reference intronic pentamer expansion in RFC1 causes CANVAS. Am J Hum Genet. 2019; 105: 151-165. 